\title{
Ethylene and Carbon Dioxide as Mediators in the Response of the Bean Hypocotyl Hook to Light and Auxins
}

\author{
B. G. Kang and P. M. RAY \\ Department of Botany, University of Michigan, Ann Arbor
}

Received January 29/April 7, 1969

\begin{abstract}
Summary. Ethylene inhibits hook opening in the bean hypocotyl and at high concentrations induces closure of the hook. Indoleacetic acid and 2,4-dichlorophenoxyacetic acid, whose inhibitory effect on hook opening resembles that of ethylene, stimulate ethylene production from the hook tissue, and this ethylene production is physiologically active in inhibiting hook opening. It is concluded that the inhibition of opening by auxin is due at least in a major part to auxin-induced ethylene production by the hook tissue.

Carbon dioxide promotes hook opening, apparently by antagonizing the action of endogenous ethylene. The concentration of respiratory $\mathrm{CO}_{2}$ in the internal gas space of the hook tissue is high enough to play a role in the regulation of hook opening.

Red light causes a decrease in ethylene production and an increase in $\mathrm{CO}_{2}$ evolution from the hook tissue. These effects are partially reversible by far-red light. It is concluded that both ethylene and $\mathrm{CO}_{2}$ serve as natural growth regulators which mediate the hypocotyl hook-opening response to light in bean seedlings.
\end{abstract}

\section{Introduction, Material and Methods}

We previously reported evidence that the photomorphogenic hookopening response of the hypocotyl of bean seedlings is regulated by ethylene and by carbon dioxide, $\mathrm{CO}_{2}$ acting as an antagonist of $\mathrm{C}_{2} \mathrm{H}_{4}$ (KANG et al., 1967). The present paper presents further data relating to the involvement of these gaseous growth regulators in the hook-opening response to light and in the inhibition of hook opening by auxins.

The plant material and the methods used were as described previously (KANG and RAY, 1969a), except as follows. Unless noted otherwise, hook opening was measured $24 \mathrm{hr}$ after the start of the experiment.

Gas Treatments. The bases of the hooks were inserted into a dish with $1 \%$ agar and the hooks were placed in a sealed desiccator (volume, 9.5 L). Ethylene was applied by injecting a measured amount with a syringe into the desiccator. For measurements of the time course of the response to ethylene, the dish containing the hooks was removed from the desiccator at intervals and shadowngraphed, then returned immediately to the desiccator into which ethylene was again injected to give the intended concentration. For treatment with fixed concentrations of $\mathrm{CO}_{2}$, a stream of air containing a known concentration of $\mathrm{CO}_{2}$ was passed continuously through the vessel during the entire experiment. 
For detection of inhibition by their own volatile products hooks were placed with their bases in agar in small vessels as described in Tables 1 and 4.

Auxin treatments were given by applying to the apical end of each hook an agar blocklet containing IAA, except in Table 5 where lanolin paste with or without IAA was applied.

Measurements of Ethylene and $\mathrm{CO}_{2}$ Output. For gas chromatographic measurements 10 hook elbow segments (comprising the curved part of the hook only, without the straight shank which is left attached in the usual hook-opening measurements) were incubated in a 60-ml Erlenmeyer flask, closed with a vaccine cap and containing $5 \mathrm{ml}$ of incubation medium. After the incubation period an 0.5 - or 1-ml sample of gas was withdrawn from the closed flask with a syringe and was injected into the gas-chromatography apparatus described by BuRa and Burg (1962).

The red-light source in the experiment of Table 2 was a tungsten lamp (150 watt) with the light passing through a glass filter (Kodak Safelight Filter, Wratten Series 1 A). The intensity was $232 \mathrm{erg} \mathrm{cm}^{-2} \mathrm{sec}^{-1}$. The far-red source was the same tungsten lamp used as red-light source, but with light passing through 2 layers each of red and blue cellophane.

The $\mathrm{CO}_{2}$ and $\mathrm{O}_{2}$ exchange measurements in Table 3 were made volumetrically by enclosing hook segments in a simple respirometer apparatus similar to that described by Thrmarn et al. (1954).

\section{Results}

Like IAA and 2,4-D, ethylene strongly inhibits hook opening both in red light and darkness, and at concentrations above $0.3 \mathrm{ppm}$, it induces a closure of hooks, as shown in Fig. 1.

The opening of hooks in red light was much reduced by keeping them in a closed chamber, especially so if an alkali trap was included to absorb respiratory $\mathrm{CO}_{2}$. The opening of such hooks was further suppressed and indeed made negative if other hooks in the same chamber were treated with IAA, suggesting that IAA promotes the production of a gaseous inhibitory substance by hook tissue. These effects were largely reversed by inclusion of mercuric perchlorate, an absorbent of ethylene, in the vessel (see Table 1). Substantial opening of hooks in a closed vessel without an alkali trap can be induced even in the dark, by including $\mathrm{Hg}\left(\mathrm{ClO}_{4}\right)_{2}$ (Table 1). These facts strongly implied that hooks release physiologically significant amounts of ethylene, and that this release is promoted by IAA and may explain the inhibition of hook opening by auxin.

Gas-chromatographic analysis showed that ethylene is produced by the hook and that IAA and 2,4-D promote ethylene output dramatically. The effect of IAA is shown in Fig. $2 \mathrm{~A}$. A promotion of ethylene production was observed by as little as $10^{-7}$ M IAA.

It had been found before that red light reduces ethylene production from the hook tissue by approximately $50 \%$ but does not affect ethylene output from the straight portion of the hypocotyl (KANG et al., 1967). 


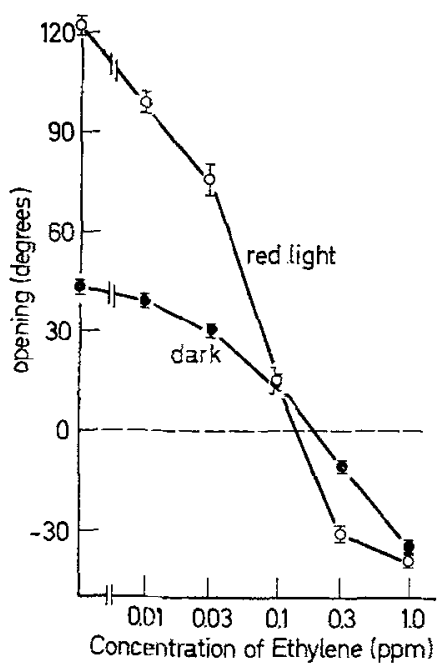

Fig. 1. Effect of ethylene concentrations on hook opening

Table 1. Effects of including IAA-treated hooks and $\mathrm{Hg}\left(\mathrm{ClO}_{4}\right)_{2}$ on opening of hooks in a closed vesse?

Treatment

Hook opening, degrees

Lot A

Lot B

Exp. 1. Red light-illuminated hooks in presence of $10 \% \mathrm{KOH}$

a) Plain agar blocks applied to $A$, none to $B$

b) IAA-agar blocks applied to $A$, none to $B$

$26 \pm 4.6$

$12 \pm 4.8$

c) As a), but $\mathrm{Hg}\left(\mathrm{ClO}_{4}\right)_{2}$ included in vessel

$-17 \pm 4.0$

$-25 \pm 4.1$

d) $\mathrm{As} \mathrm{b}$ ), but $\mathrm{Hg}\left(\mathrm{ClO}_{4}\right)_{2}$ included in vessel

$83 \pm 3.4$

$129 \pm 4.9$

Exp. 2. Hooks in dark without alkali

a) No gas absorbent

b) $\mathrm{Hg}\left(\mathrm{ClO}_{4}\right)_{2}$ included in vesse!

$32 \pm 2.6$

$118 \pm 3.3$

Hooks of lots A and B (10 hooks each) were contained within the same chamber (volume, $100 \mathrm{ml}$ ) in each of the treatments in Exp. 1. Agar blocks contained $50 \mathrm{mg} / \mathrm{l} \mathrm{IAA}$ in treatments b) and d). 20 drops of $10 \% \mathrm{KOH}$ on a filter paper wick within a vial were included in each chamber and, where shown, 20 drops af mercuric perchlorate $\left(5 \% \mathrm{HgO}\right.$ in $2 \mathrm{~N} \mathrm{HClO}_{4}$ ) in a separate vial with wick. In Exp. 2, each chamber (volume, $250 \mathrm{ml}$ ) contained 10 hooks and, in treatment b), a vessel containing $25 \mathrm{ml}$ of $\mathrm{Hg}\left(\mathrm{ClO}_{4}\right)_{2}$.

As shown in Fig. $2 \mathrm{~A}$, the effect of light on ethylene output was found also under IAA treatment, at all IAA concentrations that were tested.

The gas-chromatographic analyses also indicated that $\mathrm{CO}_{2}$ evolution from hook tissue is promoted by red light. Fig. $2 \mathrm{~B}$ shows that IAA did 

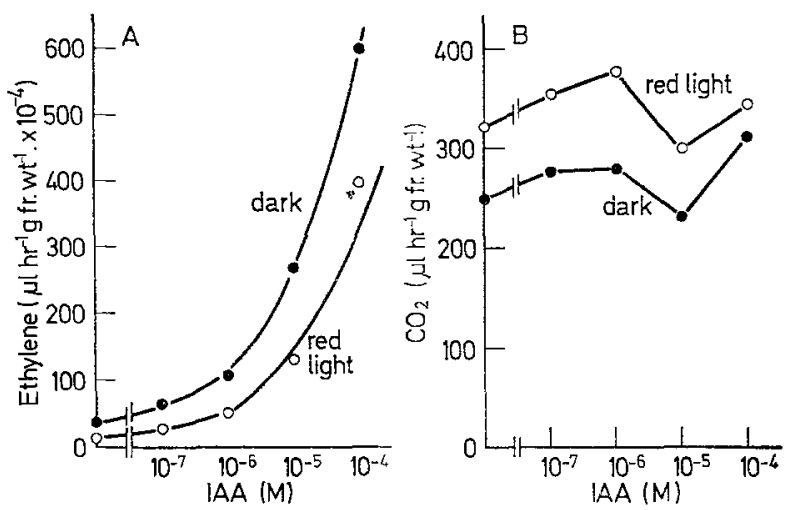

Fig. $2 \mathrm{~A}$ and B. Effect of IAA on production of ethylene (A) and $\mathrm{CO}_{2}$ (B) by hook elbow segments, measured by gas chromatographic analysis after $20 \mathrm{hr}$ incubation in a closed flask

not affect $\mathrm{CO}_{2}$ evolution substantially. These data show that the promotion of $\mathrm{CO}_{2}$ evolution by red light is not simply a consequence of growth promotion of cells on the inner side of the hook by red light, because IAA-treated hooks in which growth of these cells was completely inhibited produced in red light as much $\mathrm{CO}_{2}$ as did the rapidly growing hooks that were not treated with IAA.

The inhibition of ethylene production and promotion of $\mathrm{CO}_{2}$ evolution by red light are partially reversed by a subsequent treatment with far-red illumination (Table 2), suggesting the involvement of the phytochrome system in this response.

Fig. 3 illustrates the time-course of ethylene production in dark-, red-light-, and red-light +IAA-treated hooks. Hooks in darkness produce ethylene continuously throughout the $20-\mathrm{hr}$ incubation period whereas the production of ethylene in illuminated hooks begins to decline after $6 \mathrm{hr}$. Promotion of ethylene production by IAA is detectable at $4 \mathrm{hr}$ and becomes maximal by $6 \mathrm{hr}$.

Table 2. Reversal of red light effects on ethylene and $\mathrm{CO}_{2}$ evolution by far-red light

\begin{tabular}{|c|c|c|}
\hline & 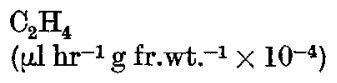 & $\begin{array}{l}\mathrm{CO}_{2} \\
\left(\mu \mathrm{l} \mathrm{hr} r^{-1} \mathrm{~g} \text { fr.wt. }{ }^{-1}\right)\end{array}$ \\
\hline Dark & 33.5 & 234 \\
\hline $\operatorname{Red}^{a}$ & 25.2 & 277 \\
\hline Red-far-redb & 31.9 & 267 \\
\hline
\end{tabular}

a Red light treatment for first $30 \mathrm{~min}$ and in dark for subsequent $15.5 \mathrm{hr}$.

b Red light treatment for first $30 \mathrm{~min}$, far-red treatment for the next $30 \mathrm{~min}$, then subsequently $15 \mathrm{hr}$ in dark. 


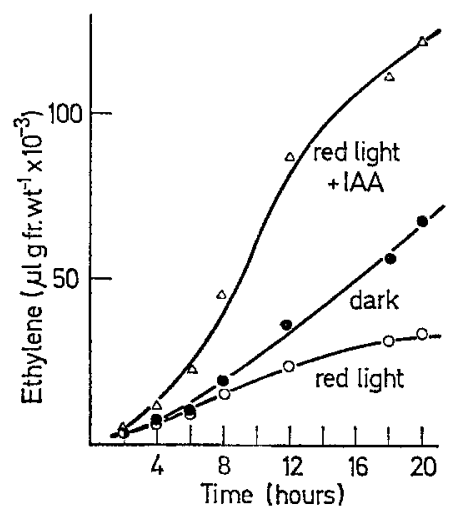

Fig. 3. Time course of ethylene production by hook ellow segments

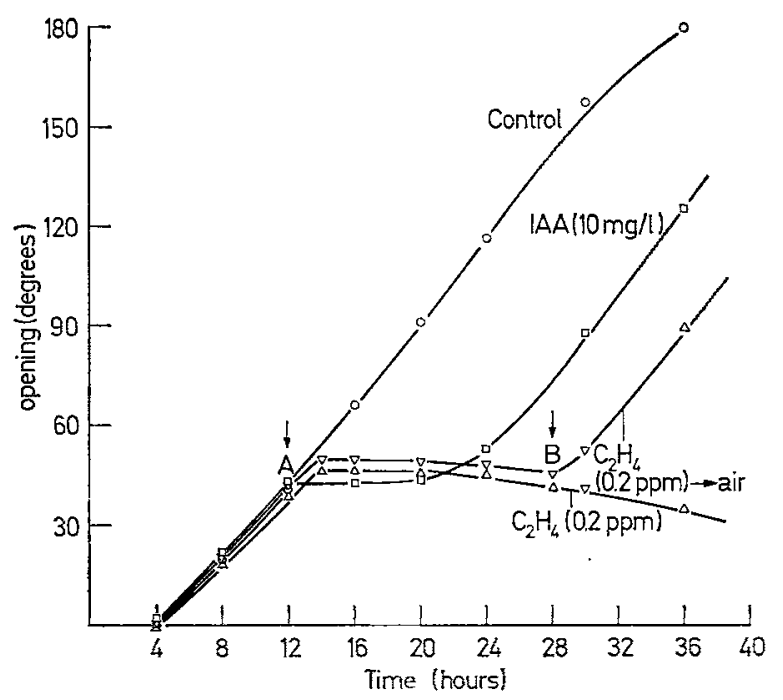

Fig. 4. Time course of effects of IAA or ethylene when applied (at arrow $A$ ) after hook opening is under way. At arrow $B$, hooks were removed from ethylenecontaining atmosphere and transfered to plain air

Fig. 4 gives the time-course for effects of IAA and of ethylene when applied after commencement of rapid light-induced hook opening. Inhibition by IAA was apparently immediate (well within $1 \mathrm{hr}$ ), but the inhibitory effect wore off after several hours. It was found in other experiments that the duration of the period of inhibition by IAA increased with the amount of IAA applied, and that if a fresh agar block containing IAA was applied after escape from previous inhibition by IAA, complete 


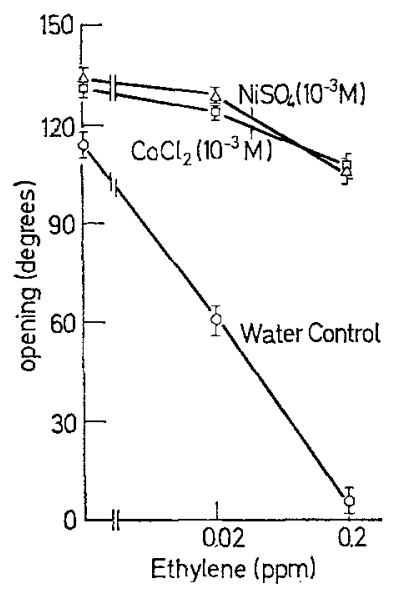

Fig. 5. Effects of $\mathrm{CoCl}_{2}$ and $\mathrm{NiSO}_{4}$ on inhibition of hook opening by ethylene

inhibition was again obtained. This indicates that inhibition by IAA is reversible and that escape from inhibition is due to disappearance of IAA from the agar block.

Inhibition by ethylene began only about $2 \mathrm{hr}$ after its application, as shown in Fig. 4. Ethylene inhibition was reversible upon removal from ethylene-containing air (Fig. 4).

Because $\mathrm{Co}^{++}$and $\mathrm{Ni}^{++}$induce hook opening in the dark and $\mathrm{Co}^{++}$ prevents inhibition of hook opening by IAA (KANG and RAY, 1969a), the effect of $\mathrm{Co}^{++}$and $\mathrm{Ni}^{++}$on the action of ethylene were tested. The results (Fig. 5) showed that $\mathrm{Co}^{++}$and $\mathrm{Ni}^{++}$largely block the response of hooks to ethylene.

The results of volumetric measurements of respiration in hook tissue are shown in Table 3 . Red light increased the rate of respiration (both $\mathrm{O}_{2}$ uptake and $\mathrm{CO}_{2}$ output) but did not affect the $\mathrm{R} Q$ significantly. Light caused about $10 \%$ increase in $\mathrm{QCO}_{2}$ within $2 \mathrm{hr}$, and the magnitude of the light effect became substantially greater with time thereafter.

The effect of $\mathrm{CO}_{2}$ upon hook opening was examined in two types of experiments. Table 4 shows that accumulation of respiratory $\mathrm{CO}_{2}$ by confining hooks in a closed vessel, in which mercuric perchlorate was included to prevent accumulation of ethylene, caused a substantial promotion of hook opening, as compared with hooks in a vessel that contained also $\mathrm{KOH}$ to prevent accumulation of $\mathrm{CO}_{2}$. Assuming that a hook produces $0.303 \mu 1$ of $\mathrm{CO}_{2}$ per minute in the darkness and $0.351 \mu \mathrm{l}$ in red light (Table 3), the accumulation of $\mathrm{CO}_{2}$ in the vessel (volume $250 \mathrm{ml}$ ) in $24 \mathrm{hr}$ would have been 1.7 and $2.0 \%$ respectively; therefore, 
Table 3. Volumetric measurements of $\mathrm{O}_{2}$ uptake and $\mathrm{CO}_{2}$ output by hook elbow segments in dark and in red light

\begin{tabular}{lllll}
\hline $\begin{array}{l}\text { Incubation } \\
\text { time after } \\
\text { excision (hr) }\end{array}$ & Condition & $\mathrm{QO}_{2}{ }^{\mathrm{a}}$ & $\mathrm{QCO}_{2}{ }^{\mathrm{a}}$ & $\mathrm{RQ}$ \\
\hline 0 & - & 0.373 & 0.350 & 0.94 \\
2 & Dark & 0.325 & 0.270 & 0.83 \\
& Red & 0.375 & 0.298 & 0.79 \\
8 & Dark & 0.303 & 0.303 & 1.00 \\
& Red & 0.385 & 0.351 & 0.91 \\
24 & Dark & 0.151 & 0.106 & 0.70 \\
& Red & 0.283 & 0.202 & 0.71 \\
\hline
\end{tabular}

a $\mu \mathrm{l} /$ hook $\times \min$.

Table 4. Effect of respiratory $\mathrm{CO}_{2}$ on hook opening in ethylene-free atmosphere

\begin{tabular}{lcr}
\hline & \multicolumn{1}{c}{ Hook opening, degrees } \\
\cline { 2 - 3 } & $-\mathrm{KOH}$ & $+\mathrm{KOH}$ \\
\hline Dark & $89 \pm 4.0$ & $51 \pm 1.9$ \\
Red light & $162 \pm 1.6$ & $124 \pm 1.7$ \\
\hline
\end{tabular}

a Ethylene was removed by including $5 \mathrm{ml} \mathrm{of} \mathrm{Hg}\left(\mathrm{ClO}_{1}\right)_{2}$ in a closed vessel (volume $250 \mathrm{ml}$ ) containing 10 hooks.

b $5 \mathrm{ml}$ of $10 \% \mathrm{KOH}$ included in the ressel.

Table 5. Opening of hooks in a flowing air stream containing fixed concentrations of $\mathrm{CO}_{2}$

\begin{tabular}{|c|c|c|c|c|}
\hline \multirow{3}{*}{$\begin{array}{l}\mathrm{CO}_{2} \\
\text { concentration }\end{array}$} & \multicolumn{4}{|c|}{ Hook opening, degrees } \\
\hline & \multicolumn{2}{|l|}{ dark } & \multicolumn{2}{|l|}{ red light } \\
\hline & no IAA & $\mathrm{IAA}^{\mathrm{A}}$ & no IAA & IAA $^{a}$ \\
\hline $\mathrm{Co}_{2}$-free air & $18 \pm 2.4$ & $4 \pm 0.9$ & $92 \pm 5.2$ & $71 \pm 5.6$ \\
\hline Air & $19 \pm 1.4$ & $10 \pm 2.2$ & $97 \pm 4.6$ & $68 \pm 4.0$ \\
\hline $3 \% \mathrm{CO}_{2}$ & $49 \pm 2.8$ & $41 \pm 1.9$ & $147 \pm 4.1$ & $109 \pm 3.6$ \\
\hline $10 \% \mathrm{CO}_{2}$ & $57 \pm 2.6$ & $56 \pm 1.7$ & $134 \pm \mathbf{3 . 3}$ & $107 \pm 3.1$ \\
\hline
\end{tabular}
hooks.

a Lanohin containing $0.1 \mathrm{mg} / \mathrm{h}$ of IAA was placed on the apical eut surfaces of

external $\mathrm{CO}_{2}$ concentrations of $1-2 \%$ evidently exert a significant promotion of hook opening.

Table 5 shows the effect of keeping hooks in an air stream containing known, constant $\mathrm{CO}_{2}$ concentrations. A nearly maximum response 
(about 30 to 40 degrees increase in opening angle) is caused by $3 \% \mathrm{CO}_{2}$ both in light and darkness, and with or without applied IAA.

The $\mathrm{CO}_{2}$ concentration in the internal gas space of hook tissue was measured by withdrawing air with a syringe from the interior of a specimen of tissue just after immersing it in water; this gas sample was analyzed by means of gas chromatography. The $\mathrm{CO}_{2}$ concentration was found to be about $10 \%$. By the same method the internal concentration of ethylene was determined to be $0.8 \mathrm{ppm}$.

\section{Discussion}

The data as a whole strongly suggest, as proposed previously (KANG et al., 1967), that auxin inhibits hook opening by inducing the production of ethylene, and that light induces hook opening by inhibiting the production of ethylene and by stimulating the production of $\mathrm{CO}_{2}$ which tends to antagonize the action of ethylene (BuRG and BuRG, 1967).

That the $20 \%$ promotion of respiratory $\mathrm{CO}_{2}$ output observed in red light is physiologically active in the hook opening response is indicated by the following considerations. According to principles of diffusional gas exchange, a $20 \%$ increase in respiratory rate should cause a $20 \%$ increase in the $\mathrm{CO}_{2}$ concentration difference between internal gas space and external air, or an increase of $2 \%(\mathrm{v} / \mathrm{v}) \mathrm{CO}_{2}$ in the internal gas space since its normal $\mathrm{CO}_{2}$ concentration was found to be $10 \%(\mathrm{v} / \mathrm{v})$ and the tissue is surrounded by air $\left(\mathrm{CO}_{2}=0.03 \% \mathrm{v} / \mathrm{v}\right)$. Application of $2 \% \mathrm{CO}_{2}$ in the air outside the tissue should also cause the internal $\mathrm{CO}_{2}$ concentration to increase by $2 \%(\mathrm{v} / \mathrm{v})$. Since $2 \% \mathrm{CO}_{2}$ in the air outside the tissue caused a substantial promotion of hook opening, it follows that the observed promotion of respiratory $\mathrm{CO}_{2}$ production by light should significantly induce hook opening.

Promotive effects of auxins on ethylene production have been reported previously for a number of plant tissues (MoRgAN and HALL, 1962; Abeides and Rubinstein, 1964; Burg and Burg, 1966), and several classic inhibitory effects of auxin have been ascribed to $\mathrm{C}_{2} \mathrm{H}_{4}$ production (Chadwick and Burg, 1967; Abeles, 1967; Burk and Burg, 1968; Burg and DiJKman, 1967). Mediation of photomorphogenic light effects by ethylene was reported for the etiolated pea plumule by GoEschu et al. (1967) and may also be involved in the light-induced expansion of etiolated bean leaf discs (Mutuer, 1952) which is inhibited by ethylene (unpublished results) and which, like hook opening, is promoted by $\mathrm{Co}^{++}$. Light effects on respiration related to photomorphogenesis have also been found in other material, though these effects have mostly been interpreted as of a secondary nature (Hock et al., 1964, 1965; PRICE et al., 1965; FRIEDERICH, 1969 and literature there cited). 
ANDREaE et $a l$. (1968) recently rejected the hypothesis of CHADWICK and BURG (1967) that inhibition of pea root growth by IAA is due to ethylene, primarily on the grounds of discrepancies between the time course of ethylene action and of auxin action on the roots. Somewhat comparable discrepancies were observed with the present system and might raise some doubts regarding the completeness of the ethylene explanation of auxin and light action.

Light induces hook opening after a latent period of somewhat less than $4 \mathrm{hr}$, while the effect of light on ethylene output could be detected only subsequent to $6 \mathrm{hr}$ (Fig. 3). A similar lag was found for the light effect upon ethylene output from etiolated pea shoots by GoEscHL et al. (1967), but they observed a much closer correspondence between the time courses for the ethylene response and the photomorphogenic reponse than can be claimed for the bean hypocotyl hook. This discrepancy is mitigated, howerer, by the fact that promotion of $\mathrm{CO}_{2}$ production by light is detectable within $2 \mathrm{hr}$, and our evidence indicates, as shown above, that this promotion significantly promotes hook opening. Thus, it is possible that the effect of light on $\mathrm{CO}_{2}$ production initiates the hook opening response while its effect on ethylene production elicits the full magnitude of the opening response. Moreover, our measurements of ethylene output by the hook elbow include much tissue other than those cells on the inner side of the hook that are the site of the photomorphogenic response. Therefore, it is also possible that local changes in ethylene production and content in these cells significantly precede the measurable changes in ethylene output by the tissue segments as a whole, thus creating a misleading discrepancy between the time-courses.

The finding that $\mathrm{Co}^{++}$and $\mathrm{Ni}^{++}$, which so strikingly induce hook opening in the dark, prevent the inhibitory action of ethylene on hook opening and also inhibit ethylene production (KANG et al., 1967), provides independent evidence that hook opening is regulated primarily by ethylene. And the fact that the ethylene hypothesis explains the otherwise puzzling promotive effects of inhibitors of protein synthesis on hook opening (KANG and RAY, 1969b) further strengthens the view that ethylene is of central importance in the opening response.

In view of the finding that $\mathrm{Co}^{++}$blocks the production and action of ethylene in the hypocotyl hook, the suppression of the auxin effect by $\mathrm{Co}^{++}$strongly suggests that the inhibitory effect of auxin on the hook is due entirely to ethylene.

It may now be suspected that the beneficial effect of $\mathrm{Co}^{++}$and $\mathrm{Ni}^{++}$ in other auxin-sensitive growth systems (Busse, 1959; MrLern, 1952; ThImaNN, 1956; CaRLIER and van Assche, 1968) is due to an interference with ethylene. This view is supported by the observation of MmLER (1954) that $\mathrm{Co}^{++}$increases the ratio of elongation to lateral expansion in 
IAA-treated pea stem segments, since the opposite effect is characteristic of ethylene (Burg and Burg, 1966). And $\mathrm{Co}^{++}$has been reported to promote growth in pea buds (HowELl and Skoog, 1955), a tissue whose growth is inhibited by auxin, an inhibition apparently attributable entirely to the ethylene production that auxin induces (BDRG and BuRG, 1967).

Data given in the previous paper (KANG and $R_{A Y}, 1969$ a) indicate that auxin is not a natural mediator of the hook opening response to light. It is clear, furthermore, that light can substantially reduce ethylene production even when it is raised far above normal by immersion of tissue in auxin at concentrations that must maintain an auxin level in the tissue far above the normal (Fig. 2A). The effect of light and of auxin on ethylene production (and thus on hook opening) must therefore be regarded as independent regulatory effects.

Previous data (KANG et al., 1967) show that at doses that promote hook opening gibberellic acid (GA) does not affect ethylene production in hook tissue [even though ABELES and RuBINSTEIN (1964) reported a stimulation of ethylene production by GA in bean internodes]. Moreover, the fact that GA does not induce opening of hooks in the dark (KANG and RAY, 1969a) indicates that GA is not acting on opening of hooks by reducing their sensitivity to ethylene. It seems clear that the GA effect is independent of ethylene. It may be suggested that GA acts simply by accelerating cell elongation and thus promotes hook opening in the light when the cells on the inner side of the hook are elongating but is unable to show any effect in the dark or in the presence of auxin because elongation of these cells is suppressed under these conditions.

The authors wish to express their thanks to Dr. S. P. BuRg, University of Miami, Miami, Florida, for his hospitality and the use of the gas chromatographic and other facilities in his laboratory, and to Dr. C. S. Yocum, Department of Botany, The University of Michigan, Ann Arbor, Michigan, for his many helpful suggestions.

\section{References}

ABELES, F. B.: Inhibition of flowering in Xanthium pensylvanicum WaLlR. by ethylene. Plant Physiol, 42, 608-609 (1967).

--, and B. Rubinsthin: Regulation of ethylene evolution and leaf abscission by auxin. Plant Physiol. 39, 963-969 (1964).

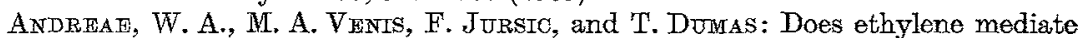
root growth inhibition by indole-3-acetic acid? Plant Physiol. 43, 1375-1379 (1968).

Burg, S. P., and E. A. BURG: Role of ethylene in fruit ripening. Plant Physiol. 37, $178-189(1962)$.

- - The interaction between auxin and ethylene and its role in plant growth. Proc. Nat. Acad. Sci. (Wash.) 55, 262-269 (1966).

- Molecular requirements for the biological activity of ethylene. Plant Physiol. $42,144-152(1967)$. 
BURG, S. P., and E. A. BuRG: Ethylene formation in pea seedlings; its relation to the inhibition of bud growth caused by indole-3-acetic acid. Plant Physiol. 43, 1069-1074 (1968).

-, and M. J. DiJkmaN: Ethylene and auxin participation in pollen induced fading of Vanda orehid blossoms. Plant Physiol. 42, 1648-1650 (1967).

Bussw, M.: Ưber die Wirkungen von Kobalt auf Streckung, Atmung und Substanzienbau in die Zellwand bei Avenakoleoptilen. Planta (Berl.) 58, 25-44 (1959).

CARLIER, A., and J. VAN AsschE: Estimation of respiration pathways, including corrections for glucuronic acid decarboxylation and label randomization; effect of l-naphthylacetic acid and cobalt chloride.Z. Pflanzenphysiol. 59, 353-363 (1968).

CHADWICK, A. V., and S. P. BURG: An explanation of the inhibition of root growth caused by indole-3-acetic acid. Plant Physiol. 42, 415-420 (1967).

FrIEDRICH, K.-E.: Untersuchungen zur Energetik der phytochrominduzierten Photomorphogenese des Senfkeimlings (Sinapis alba L.). Planta (Berl.) 84, 81-93 (1969).

Goesche, J. D., H. K. Pratr, and B.A. Bonner: An effect of light on the production of ethylene and the growth of the plumular portion of etiolated pea seedlings. Plant Physiol. 42, 1077-1080 (1967).

Hock, B., u. H. MонR: Die Regulation der $\mathrm{O}_{\mathrm{g}}$-Aufnahme von Senfkeimlingen (Sinapis alba L.) durch Licht. Planta (Berl.) 61, 209-228 (1964).

- E. KüHNeRT u. H. MoHR: Die Regulation von Fettabbau und Atmung bei Senfkeimlingen durch Licht (Sinapis alba L.). Planta (Berl.) 65, 129-138 (1965).

HowELI, R. W., and F. Skoos: Effect of adenine and other substances on growth of excised Pisum epicotyls cultured in vitro. Amer. J. Bot. 42, 356-360 (1955).

KANG, B. G., and P. M. RAY: Role of growth regulators in the bean hypocotyl hook opening response. Planta (Berl.) 87, 193-205 (1969a).

- - Effects of inhibitors of RNA and protein synthesis on bean hypocotyl hook opening and their implications regarding phytochrome action. Planta (Berl.) $87,217-226(1969 b)$.

- C. S. YocUM, S. P. BuRg, and P.M. RaY: Ethylene and carbon dioxide; Mediation of hypocotyl hook-opening response. Science 156, 958-959 (1967).

MHLER, C. O.: Relationship of the cobalt and light effects on expansion of etiolated bean leaf discs. Plant Physiol. 27, 408-412 (1952).

- The influence of cobalt and sugars upon the elongation of etiolated pea stem segments. Plant Physiol. 29, 79-82 (1954).

Morgan, P. W., and W. C. HALL: Effect of 2,4-dichlorophenoxyacetic acid on the production of ethylene by cotton plants and grain sorghum. Physiol. Plantarum 15, 420-427 (1962).

Price, L., K. MtrraKos, and W. H. KleIN : Some kinetical aspects of light-induced carbohydrate utilization in etiolated leaf tissue. Physiol. Plantarum 18, 540-549 (1965).

Thrmann, K. V.: Studies on the growth and inhibition of isolated plant parts. V. The effects of cobalt and other metals. Amer. J. Bot. 43, 241-250 (1956).

- C. S. Yocum, and D. P. HaCKETT: Terminal oxidation in potato tuber tissue. Arch. Biochem. Biophys. 53, 239-257 (1954).

Dr. BIN G. KANG

MSU/AEC Plant Research Laboratory

Michigan State University

East Lansing, Michigan 48823, USA.
Dr. Phter M. Ray

Department of Biological Sciences

Stanford University

Stanford, California 94305, USA. 